\title{
Feasibility study on the implementation of Mahalanobis-Taguchi system and time driven activity-based costing in electronic industry
}

\author{
Nik Nurharyantie Nik Mohd Kamil1', Sri Nur Areena Mohd Zaini1 ${ }^{1},{ }^{*}$, and Mohd Yazid Abu ${ }^{1}$ \\ ${ }^{1}$ Faculty of Manufacturing \& Mechatronic Engineering Technology, Universiti Malaysia Pahang, 26600 Pahang, Malaysia.
}

ABSTRACT - Electrical and electronic industry is one of Malaysia's leading industries which covers around $24.5 \%$ in manufacturing production sector. With a continuous innovation of the Industry, inductor component gets higher demand from customer and it is good if there is a study to convince that those factors are really significant to the production as well. Meanwhile, the current costing being used is difficult to access the complete activities required for each workstation and need separate analysis to measure the un-used capacity in term of resources and cost. The objective of this work is to clarify the relationship between Mahalanobis-Taguchi system (MTS) and time driven activity-based costing (TDABC) in the electronic industry. The data collection is focused on inductor component by consiedring the historical data in 2018. MTS is used as a method to optimize various parameters while TDABC is used to measure the un-used capacity by constructing the time equation and capacity cost rate. There are 7 parameters considered which are condition of wire, condition of winding, condition of epoxy, condition of core, condition of lead part, condition of marking and condition of soldering. As a result, MTS is successfully developed the normal and abnormal Mahalanobis distance (MD). In February, the normal MD is 0.9998 and the abnormal is 15.6538 with 2 significant parameters with signal to noise is 0.1244 . In addition, there are 3 parameters consistently influenced along 10 months such as condition of core, condition of lead part and condition of soldering and 2 parameters are not consistently influenced such as condition of epoxy and condition marking. On the other hand, the total used and un-used capacity of time are 257124.02 minutes and 5217031.43 minutes respectively while the total of used and un-used of cost are MYR6,296,493.10 and MYR6214807.07 respectively. Eventually, this work concludes that both methods are a great tool and feasible to be implemented in the electronic industry.
ARTICLE HISTORY

Received: 26-1-2021

Revised: 4-2-2021

Accepted: 4-3-2021

\section{KEYWORDS}

Mahalanobis-Taguchi system

Optimization

Time driven activity-based

costing

Time equation

Capacity cost rate

\section{INTRODUCTION}

Industry 4.0 has been important for stimulating industrial and economic growth and for Malaysia's economy to achieve a RM2 trillion target over the next eight years, according to the Malaysian Ministry of International Trade and Industry. In an attempt to change the production environment in Malaysia by minimising manual labour dependence and ensuring competitive exports, Malaysia manufacturers are being urgedto automate and adopt the fourth industrial revolution. With a continuous innovation of the Industry, inductor component gets higher demand from customer and it is good if there is a study to convince that those factors are really significant to the production as well. Meanwhile, the current costing being used is difficult to access the complete activities required for each workstation and need separate analysis to measure the un-used capacity in term of resources and cost.

In 1936, the Mahalanobis distance (MD) which introduced by an Indian statistician Prasanta Chandra Mahalanobis to classify members of a group identified by characteristics, taking into account a system's correlation structure that could or could not be corresponded. Whereas, Su and Hsiao in 2009 said that Genichi Taguchi introduced the strong engineering of Taguchi in the 1950s to enhance the engineering efficiency that can be calculated in terms of deviations from the ideal performance. Genichi Taguchi subsequently incorporated the concept into the Mahalanobis-Taguchi (MTS) method for robust engineering by laying out a way of identifying the reference category and calculating the degree of abnormality of the individual observations. Taguchi and Jugulum (2000) used a case study of liver disease diagnosis in Tokyo, Japan with 15 variables to apply the MTS for the diagnosis and pattern recognition problem and created an 8-step procedure entitled "Mahalanobis distance for diagnosis and pattern recognition system optimization procedure".Basically, the MTS is a technology for pattern recognition that aids in quantitative decisions by using a data analytical approach to create a multivariate measurement scale. Multivariate data on a normal group of items and a number of abnormal items must be available, which can sometimes be divided into categories according to the magnitude of abnormality levels (Woodall et $\mathrm{al}, 2003)$. In this method, MD acts as a tool to evaluate the resemblance, define and examine various trends concerning the mean of the reference space as a discriminating research approach focused on correlations between variables. Then, by building a measurement scale, MD is accustomed to make a precise forecast in multi-scale structure. There are primarily three phases of the MTS technique. First of all, the reference space, which is a benchmarking group of normal 
data, is selected and its MD is determined for each sample. Abnormal data has to be chosen in the second level. The larger MD values obtained from abnormal normal data showed that the scale was fine. The final stage requires a method of optimization. The number of variables can be decreased by using the orthogonal array and S/N ratio when the assessment of input of each variable on the factorial effect graph are made. The benefit of MD is that the associations between any variables during the normalization process and very economical for multidimensional pattern recognition systems are taken into account (Cudney and Corns, 2011). The method is well founded because the MD values are critically important for the identification and segregation of faults (Wang et al, 2012) and the measurement of MD values does not require substantial computational requirements, which implies that the technique can be apply instantaneous (Wang et al, 2013). Since the MD value is determined from the mean of the samples in terms of standard deviations, it issues a statistical count of effectiveness for an unknown sample complements or is adjacent to the known sample collection. The essential variables of a multivariate system (Cudney et al, 2006) are also defined by MTS because the Taguchi methods are extremely efficient in lessening the unnecessary characteristics and removing the key components by implementing the $\mathrm{S} / \mathrm{N}$ ratio of typical variables according to the orthogonal array of two stages. Therefore, without losing process efficiency, MTS can be used for production advancement, particularly in quality assessment for advance mechanization industries.

\section{LITERATURE REVIEW}

A few problems have been highlighted to expose the shortcomings of MTS, according to Woodall et al (2003). In terms of conceptuality, MTS is considered ad hoc since no underlying mathematical principle is used to construct the method. Taguchi and Jugulum (2000) did not equate the MTS with other statistical multivariate approaches, but only mentioned that their system is quite distinct. There is no statement regarding the input variable distribution. For example, it is not assumed that the data vectors are normal in multivariate terms. For modeling the observations, the uncertainty of statistics or the predicted losses, no probability distributions are used. No operational meaning is provided for "higher than" with respect to operational. If normal and abnormal objects are not easily distinguishable, then it seems that probabilities of misclassification must be taken into account, something not feasible under the MTS system that prevents the use of probability. However, the run for which all variables are at their low levels is not a true run because in the analysis, at least one variable must be used. An OA containing this run could not, therefore, be used. Finally, with regard to technical matters, Taguchi and Jugulum (2000) confirmed that unity is the average value of MDs for ordinary objects. Several works are linked to MTS. Abu et al (2014) applied MTS to the large-end connecting rod diameter to differentiate between two distinct ranges within the spectrum of the re-manufacturability process. A systematic study of the data set on the main crankshaft log diameter was given by Abu and Jamaludin (2014). Mohd Yazid et al (2015) provided systematic pattern recognition using MTS by constructing a scatter diagram that could assist industry-specific decisionmaking on 14 main crankshaft journals belonging to 7 engine models with different sample numbers. Abu et al (2017) categorized the end life of crankshafts into MTS related recovery operations. Nik Mohd Kamil and Abu (2018) and Abu et al (2018) created a distinctive crankshaft pattern and defined the MTS-based critical and non-critical crankshaft parameter, then applied the Activity Based Costing (ABC) as a method of estimating the crankshaft remanufacturing rate. The criticality of end of life crankshaft parameters based on Taguchi's orthogonal array was assessed by Abu et al (2018). Then, by considering the essential parameters, determine the value using conventional cost accounting. The degree of abnormality using MTS was calculated by Azmi et al (2019) and the parameters that affect the mechanism were diagnosed. In the electrical and electronic industries, Nik Mohd Kamil et al (2020) and Mohd Safeiee et al (2020) proposed MTS and Time-Driven Activity-Based Costing to evaluate the important parameters and respectively build time equation and power cost rate.

In the cost evaluation of the conventional cost accounting system, activity-based costing (ABC), which was introduced by Kaplan and Cooper in the early 1980s, resolves the problems of cost distortion and cost subsidization. It implies that the allocation basis is volume-based for all related production costs. Hernandez-Matias et al (2006) pointed out that one of the key methodologies and instruments for evaluating the production environment and supporting the decision-making process is the $\mathrm{ABC}$ costing model. There are two main phases at $\mathrm{ABC}$. The first stage allocates the indirect costs to the activity centers and the second stage, using the activity drivers, assigns the assigned costs of these centers to the cost items. Lea and Fredendall (2002) contrasted the conventional cost accounting system, ABC and constraint theory and found that these cost accounting management systems vary substantially when used with cases of different forms of output, product types, degrees of automation and methods of allocating overhead costs of production. In various ways, they also define 'production cost'. The conventional cost accounting system is only appropriate for mass production but is not sufficient for the production of diversified goods because, due to a biased cost calculation, it can lead to an erroneous pricing decision in which costs are not positively associated with quantity. In the conventional cost accounting system, ABC strengthened this weakness, particularly when there are diversified goods and the overhead production is high because not all production costs are purely quantity-relevant in practice (Chang et al, 2014). There are some works had been done in ABC. A discontinuous piecewise linear feature with full progressive carbon emission tax rates was used by Tsai and Jhong (2019) to increase the efficiency of operations across a variety of product mixes. Research by Defourny et al (2019) suggested that conventional ABC is 68.4 percent of the cost and 31.6 percent of treatment planning is also able to reliably calculate the treatment delivery activities. Phan et al (2018) proposed that organizations should concentrate on evaluating environmental impact activities, controlling them through their cost drivers, and allocating costs to goods and services for environmental activities. Allain and Laurin (2018) found that the characteristics of cost structures needed to satisfy regulatory needs are different from those necessary to support decision-making, and these criteria are likely to 
prevail over those of decision-makers because regulatory needs are typically prioritized. Abu et al (2017) estimated the cost of remanufactured crankshaft using ABC while Nik Mohd Kamil and Abu (2018) and Abu et al (2018) developed a distinctive pattern of crankshaft and identify the critical and non-critical parameter of crankshaft based on the Mahalanobis Taguchi System, then applied the ABC as a method of estimation for the remanufacturing cost of crankshaft. Zheng and Abu (2019) applied the ABC as a method of cost estimation for the palm oil plantation and Zamrud et al (2020) performed a comparative study for electronic component between $\mathrm{ABC}$ and time-driven activity-based costing. Currently, Zaini et al (2020) applied the ABC as a method of cost estimation for the palm oil plantation and it makes the company's profitability more accurate.

Time-driven activity-based costing (TDABC) is an accounting approach that has gained market traction and is becoming increasingly prominent as a tool for estimating the cost of delivery of healthcare (Kaplan et al, 2014). TDABC helps healthcare providers over a full longitudinal treatment period to assess the costs of treating patients with a particular medical or surgical condition. This utilizes industrial engineering process mapping and activity-based accounting costs (Anzai et al, 2017). The TDABC model allows multiple cost layers to be accounted for, enabling a more nuanced analysis of cost contributors than current estimates, such as relative value units and ratios of charge-cost. TDABC makes it possible to both define cost-driving steps in a process and to analyze cost-reduction strategies. In fact, estimates of time and capacity cost rates only needed for the TDABC calculations which are straightforward (Kaplan, 2014). The application of TDABC has been validated through many research works. In case of cost variation in the health care, Haas and Kaplan (2017) found that TDABC still provided accurate estimation in care cycle cost. Afonso and Santana (2016) presented a cost model using TDABC associated with multiple time equations and discussed the profitability at different cost objects. $\mathrm{Yu}$ et al (2016) found that TDABC resulted in precise cost and identified inefficiencies in health care. Mohd Zaini and Abu (2019) explored the research gap of TDABC among published works that can be used as guideline in applying TDABC system in palm oil plantation. Zamrud et al (2020), Nik Mohd Kamil et al (2020) and Mohd Safeiee et al (2020) analyzed the manufacturing cost of electronic components incurred on production in electric and electronic industry using TDABC. Currently, Ghani et al (2020) identified the used and unused capacity in the production line using TDABC. Station with overused capacity and several stations with underused capacity gives a clear overview to the management of the company for better investment strategy. In work by Zamrud et al (2020) compared the advantages of ABC and TDABC by analysing the features towards the costing sustainment and it concluded that both have their power in line with the needs of the industry.

\section{OBJECTIVE}

The objective of this work is to apply the method of MTS and TDABC on the inductor component in the electronic industry. MTS is used as a method to optimize various parameters while TDABC is used to measure the un-used capacity by constructing the time equation and capacity cost rate. Eventually, this work concludes that both methods are a great tool and feasible to be implemented in the electronic industry.

\section{METHODOLOGY}

This work is conducted at a company located at Pahang, Malaysia as a leading supplier of electronic components for essential performance solutions. MTS has been formed into four phases, as reported by Ghasemi et al (2015):

Stage 1: Construction of measurement scale with the Mahalanobis space (normal space) as a reference. The feature data was obtained for the normal data set from healthy products. The reference space is defined as MS which constituted by Mahalanobis distance (MD)s as shown in Equation (1). The value of MDs is around one.

$$
\mathrm{MD}_{\mathrm{i}}=\frac{1}{\mathrm{n}} \mathrm{z}_{\mathrm{i}} \mathrm{C}^{-1} \mathrm{z}_{\mathrm{i}}^{\mathrm{T}}
$$

where $\mathrm{zi}=\left[\mathrm{z}_{\mathrm{i} 1}, \mathrm{Z}_{\mathrm{i} 2}, \ldots, \mathrm{z}_{\mathrm{in}}\right]$, can be defined as transpose vector of $\mathrm{zi}$, and $\mathrm{C}^{-1}$ is the inverse of the covariance coefficient matrix C.

\section{Stage 2: Validation of MS.}

Abnormal condition findings are selected first. Their function data sets are normalized using the normal data set's mean and standard deviation. Then, using the normalized function data and the matrix of the covariance coefficient of the normal data collection, the MDs are determined. The MD referring to the pathological condition would then be considered as being outside of MS. In other words, these abnormal conditions associated MDs will have higher values.

\section{Stage 3: Optimization.}

Using orthogonal arrays (OAs) and signal-to-noise ratios ( $\mathrm{S} / \mathrm{N}$ ratios), the useful characteristics are chosen. By minimizing the different combination of original features, OAs are used to classify the significant features. In OAs, the number of columns depends on the number of functions. There are two level variables composed of OAs that are level 1 and level 2. Level 1 can be defined as the function used to include the calculation feature, while level 2, which means removing the feature in the calculation, is to be described as unused. The $\mathrm{S} / \mathrm{N}$ ratios were only determined with the 
abnormal state. Equation (2) shows the formula for calculating the $\mathrm{S} / \mathrm{N}$ ratio $\left(\eta_{\mathrm{i}}\right)$ that corresponding to the ith run of the OA.

$$
\eta_{i}=-10 \log \left(\frac{1}{t} \sum_{j=1}^{t} \frac{1}{M_{j}}\right)
$$

where $t$ is the number of abnormal conditions, and $\mathrm{MD}_{\mathrm{j}}$ is the $\mathrm{MD}$ of the jth abnormal condition. Then, evaluating of the "Gain" in S/N ratios will obtain the useful features. Equation (3) shows the calculation of "Gain" and the feature that come out with positive gain is identified as the useful features.

$$
\text { Gain }=\overline{\mathrm{S} / \mathrm{N} \text { ratıo }} \text { Level } 1_{1}-\overline{\mathrm{S} / \mathrm{N} \text { ratıo } \text { Level }_{2}}
$$

Stage 4: Diagnosis and prognosis.

The reconstructed MS and the tracked product MDs are determined at this stage using the useful features identified in stage 3. If the value of MDs is inside the MS, the normal product will be considered by the monitor product, while the value of MDs is beyond the MS, abnormal behaviors will be considered by the product. In short, the higher the MDs, the greater the difference between the product monitored and standard.

According to Erhun et al (2018), TDABC has seven steps which are select the product, develop process map for each workstation, determine the time estimation for each process, estimate the cost resources supplied, calculate the total product cost, and the last step is optimize the capacity planning. The first step is selecting the product that to apply TDABC concept. This selection must be based on the condition of activities that contribute to the production process because of the different style and condition of different company and organization. Therefore, measuring the unused capacity in term of resources and time are very important to increase the profit margin in all the company. This is because the company is lack of knowledge about the TDABC system that up-to-date to apply in industry especially in electronic industry. The second step is developing the process map for each workstation. The process map is very important and systematic for all each workstation to avoid the problem such as delay process or any mistaken that cause by the workers in industry. This is because these problems will cause unsmooth of the process in each workstation to produce the product. The third step is to determine the time estimation for each process to produce the product. This is because the time estimation is different from sharing a same process with a same component. In fact, time is very closely related to the cost. Therefore, timing is a big issue in production industry because if one time is delay of process it will affect and delay all the activities in a production in a certain time. Besides, timing also can make the company forecast to the future for the product. Next step is to estimate the product cost resources supplied. Logically, all the industries in Malaysia or other countries have their own regular supplier. So, it is very important in production process must be on track with on time to avoid delay in production department. Consequently, time equation also will be used to calculate and estimate the cost based on the product cost resources supplied. Estimation the capacity of each resources and calculate the capacity cost rate is the next step of TDABC system. Equation (4) shows a calculation of capacity cost rate which is the main calculation in TDABC system that will provide good ability in a business operation. In order to get the smooth process, the capacity of each resources must be check regularly. The capacity cost rate also can increase the expectation of market demand in worldwide business for industry.

$$
\text { Capacity cost rate }=\frac{\text { Cost of capacity supplied }}{\text { Practical capacity of resources supplied }}
$$

Sixth step is calculating the total product cost. In business, although the cost is cheap, the quality is good. So, the quality is not based on the cost which the large amount the cost, the better quality sometimes cannot be acceptable. In a conclusion, the company will know the profit and the rate of product on the market. Finally, optimization the capacity planning is the last step of TDABC system. This estimated capacity is required by each activity center that determined by quantifying the frequency of the activity in month.

\section{RESULT AND DISCUSSION}

MTS is used as a method to optimize various parameters on the inductor component in the electronic industry. Initially, this work needs to develop the normal and abnormal group to observe the pattern distribution. Figure 1 shows the MD of normal and abnormal for in 2018 generated using Matlab Software. The red colour indicates the normal MD while the black colour indicates the abnormal MD. 


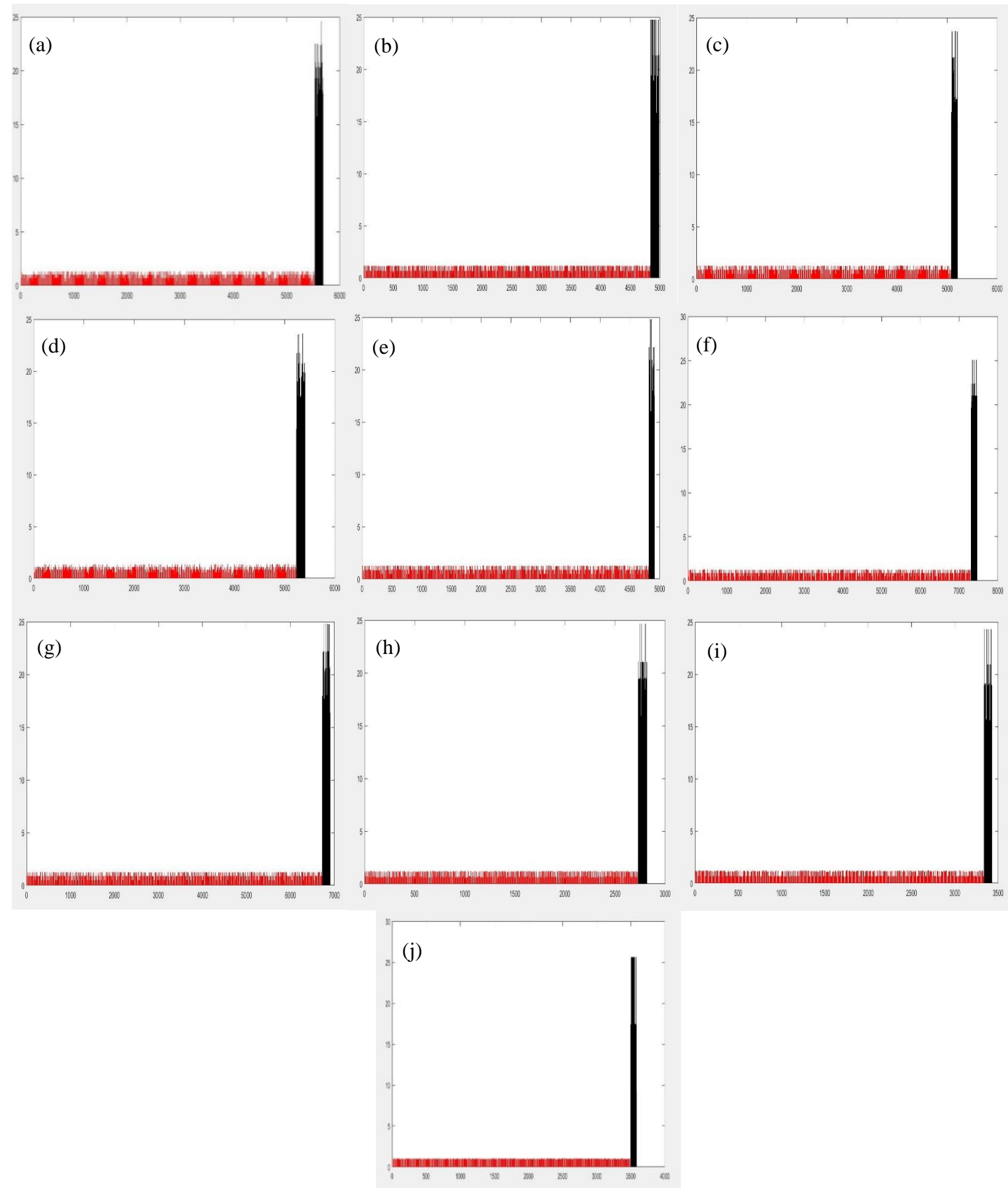

Figure 1. Normal and abnormal MD on (a) February, (b) March, (c) April, (d) May, (e) June, (f) July, (g) September, (h) October, (i) November and (j) December 2018.

In February, MD for normal group is 0.9998 while for abnormal group is 15.6538 with 2 parameters influence in this workstation. Then, the value of SNR gain is 0.1244 indicates both parameters significantly affect the system. In March, the MD for normal group is 0.9998 while MD for abnormal group is 16.9787 . Both values obviously show the distictive pattern between normal and abnormal distribution. There are 4 parameters significantly influence in this workstation with SNR gain is 0.1914. In April, the MD for normal group is 0.9998 while the MD for abnormal group is 15.5546. The MD of normal is closely to 1 indicates the normal is unity to the abnormal. The value of SNR gain is 0.1338 with 3 parameters significantly influence the system. In May, the MD for normal group is 0.9998 while the MD for abnormal group is 16.2691. Higher the MD value of abnormal group indicates that it has high difference of characteristic from the normal group. In this condition, only one parameter influences to this workstation with positive gain which is 0.0439 . In June, the MD for normal group and abnormal group are 0.9998 and 16.3283 respectively. The SNR gain shows 0.0968 with 3 parameters influence the system. Subsequently in July, the MD for normal group is 0.9999 and MD for abnormal is 16.4914. There are 3 parameters influence the system with SNR gain is 0.2344 . Technically, the company is not provided 
the data in January and August due to unknown reasons. In September, the MD for normal is 0.9999 and the MD for abnormal is 16.2278. As for now, the range for abnormal is in between 15 to 20 . It means there are a similarity in their pattern among the abnormal groups. At this time, only 3 out of 7 parameters significantly influence the system with the SNR gain is 0.1748 . In October, the MD for normal group is 0.9996 while the MD for abnormal group is 16.6988 . There are 4 out of 7 parameters are significantly influence the system with the SNR gain is 0.3202 . In November, the MD for normal and abnormal are 0.9997 and 16.1046 respectively. There are 3 parameters significantly influence in this workstation with SNR gain is 0.3295. Finally, the MD for normal and abnormal group is 0.9997 and 18.2141 respectively in December. The value of SNR gain is 0.4432 with 2 parameters significantly influence to the system.

As mention earlier, there are 7 parameters are considered such as condition of wire, condition of winding, condition of epoxy, condition of core, condition of lead part, condition of marking and condition of soldering. Table 1 shows the significant and insignificant parameter by marking as $(\sqrt{ })$ and $(\times)$ respectively for each month together with the value of SNR gain. The significant parameter refers to the critical parameter to reject the component. Based on Table 4.13 , there are 3 major significant parameters which effecting the quality of inductor component namely condition of core, condition of lead part and condition of soldering. On the other hand, there are 2 inferior parameters that are not significantly effecting the quality of the inductor component namely condition of wire and condition of epoxy. The more significant parameters, the highest SNR gain value. From the table also, the highest SNR gain value is 0.4432 in December 2018 while the lowest SNR gain is 0.0439 which is recorded in May 2018. There are 5 significant parameters which are related to the highest SNR gain value namely condition of wire, condition of epoxy, condition of core, condition of lead part, and condition of soldering. For lowest gain, only one parameter is considered to be rejected which refers to condition of core.

Table 1. Significant, Insignificant parameters and SNR gain.

\begin{tabular}{cccccccccc}
\hline \multirow{2}{*}{ Month } & \multicolumn{8}{c}{ Parameter } & \multirow{2}{*}{ SNR Gain } \\
\cline { 2 - 6 } & 1 & 2 & 3 & 4 & 5 & 6 & 7 & \\
\hline February & $\times$ & $\times$ & $\times$ & $\sqrt{ }$ & $\sqrt{ }$ & $\times$ & $\times$ & 0.1244 \\
March & $\sqrt{ }$ & $\times$ & $\sqrt{ }$ & $\sqrt{ }$ & $\times$ & $\times$ & $\sqrt{ }$ & 0.1914 \\
April & $\times$ & $\times$ & $\times$ & $\sqrt{ }$ & $\sqrt{ }$ & $\times$ & $\sqrt{ }$ & 0.1338 \\
May & $\times$ & $\times$ & $\times$ & $\sqrt{ }$ & $\times$ & $\times$ & $\times$ & 0.0439 \\
June & $\times$ & $\times$ & $\times$ & $\sqrt{ }$ & $\times$ & $\times$ & $\sqrt{ }$ & 0.0968 \\
July & $\times$ & $\times$ & $\times$ & $\sqrt{ }$ & $\sqrt{ }$ & $\times$ & $\sqrt{ }$ & 0.2344 \\
September & $\times$ & $\times$ & $\times$ & $\sqrt{ }$ & $\sqrt{ }$ & $\times$ & $\times$ & 0.1748 \\
October & $\times$ & $\times$ & $\sqrt{ }$ & $\sqrt{ }$ & $\sqrt{ }$ & $\times$ & $\times$ & 0.3202 \\
November & $\times$ & $\times$ & $\times$ & $\sqrt{ }$ & $\sqrt{ }$ & $\times$ & $\sqrt{ }$ & 0.3295 \\
December & $\sqrt{ }$ & $\times$ & $\sqrt{ }$ & $\sqrt{ }$ & $\sqrt{ }$ & $\times$ & $\sqrt{ }$ & 0.4432 \\
\hline
\end{tabular}

There are 16 production processes at different workstations that must go through in order to produce inductor component. The first process starts with drum core winding which is equipped with auto epoxy, followed by other 15 processes namely convection oven and cooling process, lead cutting \& lead adjustment, assembling drum core to shield core, epoxy application, epoxy inspection, IR reflow \& cooling process, part number marking, termination \& trimming, dip soldering, ultrasonic-cleaning \& cooling process, first visual mechanical inspection, co-planarity check, inductance test, and tape and reel. In this validation process, the types of supplied resources refer to the labor cost, material cost, maintenance cost, and consumable cost. Table 2 summaries the total supplied resources for each workstation in the process of producing inductor component.

Table 2. Resources supplied of inductor component.

\begin{tabular}{|c|c|c|c|c|c|}
\hline Workstation & $\begin{array}{l}\text { Labor cost } \\
\text { (MYR) }\end{array}$ & $\begin{array}{c}\text { Maintenance } \\
\text { cost } \\
\text { (MYR) }\end{array}$ & $\begin{array}{l}\text { Material cost } \\
\quad(\text { MYR) }\end{array}$ & $\begin{array}{c}\text { Consumable } \\
\text { cost } \\
\text { (MYR) }\end{array}$ & $\begin{array}{c}\text { Cost of all } \\
\text { resources } \\
\text { supplied } \\
\text { (MYR) } \\
\end{array}$ \\
\hline 1.Drum core winding with auto epoxy & 33,000 & nil & $5,832,614.40$ & 3,636 & $5,858,250.40$ \\
\hline 2.Convection oven $\&$ cooling process & 11,000 & nil & nil & nil & 11,000 \\
\hline 3. Lead cutting \& Lead adjustment & 11,000 & nil & $12,794.40$ & nil & $23,749.40$ \\
\hline 4.Assemble drum core to shield core & 22,000 & nil & $51,507.58$ & nil & $73,507.58$ \\
\hline 5.Epoxy application & 11,000 & nil & nil & 3,636 & 14,636 \\
\hline 6.Epoxy inspection & 22,000 & nil & nil & $1,581.60$ & $23,581.60$ \\
\hline 7.IR reflow \& cooling process & 11,000 & nil & nil & nil & 11,000 \\
\hline 8.Part number marking & 11,000 & nil & nil & nil & 11,000 \\
\hline 9.Termination \& trimming & 22,000 & nil & nil & nil & 22,000 \\
\hline 10. Dip soldering & 11,000 & $8,197.60$ & nil & $8,197.60$ & $27,395.20$ \\
\hline $\begin{array}{l}\text { 11.Ultrasonic-cleaning \& cooling } \\
\text { process }\end{array}$ & 11,000 & nil & nil & $1,581.60$ & $12,581.60$ \\
\hline $\begin{array}{l}\text { 12. Final Visual Mechanical } \\
\text { Inspection }\end{array}$ & 55,000 & nil & nil & nil & 55,000 \\
\hline 13.Co-planarity check & 22,000 & nil & nil & nil & 22,000 \\
\hline
\end{tabular}




\begin{tabular}{lcccc}
\hline 14.Inductance test & 11,000 & nil & nil & nil \\
15. Tape and reel & 11,000 & nil & $64,172.26$ & nil \\
16. Packaging & 11,000 & nil & $33,619.06$ & $75,172.26$ \\
\hline
\end{tabular}

The total supplied resources spent to produce the inductor component is indicated as MYR6,296,493.10 per year. For a total of 16 workstations, these processes require 30 operators to complete a unit of inductor component. As informed by the company, the production line operates in 10 months within a year. The company's working hours are from Monday to Saturday with 2 shifts. Each shift takes about 8 hours 50 minutes per day which is from 8 am to 5.30 pm and another shift takes from $8 \mathrm{pm}$ to $5.30 \mathrm{am}$. The working day per month is 20 days. The working times are considered as the standard working time with deduction of breaks and overtime. A total of 23 public holidays are also deducted in the calculation process. Further, Table 3 summaries the time equation for results validation of the inductor component.

Table 3. Time equation of inductor component.

\begin{tabular}{|c|c|c|}
\hline Workstation & Sub-Activities & Time equations \\
\hline 1.Drum core winding & 1.Install the core into the chuck of the winding machine & $0.067 \mathrm{X}_{1}$ \\
\hline \multirow[t]{2}{*}{ with auto epoxy } & 2.Move the finish unit and hang to curing fixture. & $0.1 \mathrm{X}_{2}$ \\
\hline & 3.Transfer the curing fixture into the curing oven & $0.13 \mathrm{X}_{2}$ \\
\hline 2.Convection oven and & 1.Transfer the curing fixture fill of units and put it into curing oven & $0.13 \mathrm{X}_{2}$ \\
\hline \multirow[t]{3}{*}{ cooling process } & 2.Curing the epoxy & $45 \mathrm{X}_{3}+30 \mathrm{X}_{4}$ \\
\hline & 3.Dry the unit below the cool fan & $15 \mathrm{X}_{5}+5 \mathrm{X}_{6}$ \\
\hline & 4.Transfer the unit into the tray & $0.03 \mathrm{X}_{7}$ \\
\hline 3.Lead cutting \& Lead & 1.Cool down the units after curing process & $15 \mathrm{X}_{5}+5 \mathrm{X}_{6}$ \\
\hline \multirow[t]{2}{*}{ adjustment } & 2.Transfer the units into the tray for lead cutting process & $0.03 \mathrm{X}_{8}$ \\
\hline & 3.Put the part in the vacuum tray after cut and adjust process & $0.03 \mathrm{X}_{8}$ \\
\hline 4.Assemble drum core to & 1.Transfer the drum core into the tray & $0.05 \mathrm{X}_{9}$ \\
\hline shield core & 2.Transfer the travel bar into $x-y$ table & $0.25 \mathrm{X}_{10}$ \\
\hline \multirow[t]{2}{*}{ 5.Epoxy application } & 1.Clean the end of EFD needle using soft material cloth & $0.13 \mathrm{X}_{11}$ \\
\hline & 2.Remove the travel tray from the machine & $0.15 \mathrm{X}_{12}$ \\
\hline \multirow[t]{3}{*}{ 6.Epoxy inspection } & 1.Transfer the travel tray from $x-y$ table under CCTV for inspect & $0.15 \mathrm{X}_{12}$ \\
\hline & 2.Change the cotton bud for cleaning tool if in bad condition & $0.167 \mathrm{X}_{13}$ \\
\hline & 3.Transfer the travel tray to the curing oven for epoxy curing process & $0.2 \mathrm{X}_{14}$ \\
\hline 7.IR reflow and cooling & 1.Transfer the travel tray fill of units and put it into curing oven & $0.2 \mathrm{X}_{14}$ \\
\hline \multirow[t]{2}{*}{ process } & 2.Curing the epoxy & $45 \mathrm{X}_{3}+30 \mathrm{X}_{4}$ \\
\hline & 3.Dry the unit below the cool fan & $15 \mathrm{X}_{5}+5 \mathrm{X}_{6}$ \\
\hline \multirow[t]{2}{*}{ 8.Part number marking } & 1.Transfer the unit with travel tray that had been cool down into laser machine & $0.42 \mathrm{X}_{15}$ \\
\hline & 2.Transfer the units into tray for next process & $0.05 \mathrm{X}_{16}$ \\
\hline \multirow{2}{*}{$\begin{array}{l}\text { 9.Termination \& } \\
\text { trimming }\end{array}$} & 1.Transfer the units from the travel bar into vacuum tray & $0.05 \mathrm{X}_{17}$ \\
\hline & 2.Transfer the units by using vacuum tray to avoid fall & $0.05 \mathrm{X}_{18}$ \\
\hline \multirow[t]{3}{*}{ 10.Auto-dip soldering } & $\begin{array}{l}\text { 1.Transfer the vacuum tray with units from cut and trim workstation to } \\
\text { soldering process }\end{array}$ & $0.25 \mathrm{X}_{18}$ \\
\hline & 2.Transfer the unit from vacuum tray to the solder fixture & $0.2 \mathrm{X}_{19}$ \\
\hline & 3.Transfer the unit for cleaning process & $0.58 \mathrm{X}_{20}$ \\
\hline \multirow[t]{5}{*}{$\begin{array}{l}\text { 11.Ultra-sonic cleaning } \\
\text { and cooling process }\end{array}$} & $\begin{array}{l}\text { 1.Transfer the unit from soldering workstation for cleaning process using } \\
\text { ultrasonic machine }\end{array}$ & $0.58 \mathrm{X}_{21}$ \\
\hline & 2.Transfer the unit into the glass beaker, fill with isopropyl alcohol & $0.17 \mathrm{X}_{22}$ \\
\hline & 3.Transfer the glass beaker into the ultrasonic machine & $0.05 \mathrm{X}_{23}$ \\
\hline & $\begin{array}{l}\text { 4.Transfer out the unit using filter to remove the isopropyl alcohol and put on } \\
\text { the tray }\end{array}$ & $0.17 \mathrm{X}_{24}$ \\
\hline & 5.Dry up the unit under the cooling fan & $15 \mathrm{X}_{5}+5 \mathrm{X}_{6}$ \\
\hline \multirow[t]{3}{*}{ 12.Final VMI } & $\begin{array}{l}\text { 1.Transfer the unit after cooling process into VMI process by using magnet } \\
\text { strip }\end{array}$ & $0.75 \mathrm{X}_{25}$ \\
\hline & 2.Transfer the unit part into vacuum tray after inspect & $0.03 \mathrm{X}_{26}$ \\
\hline & 3.Transfer the unit part into co-planarity check & $0.67 \mathrm{X}_{27}$ \\
\hline \multirow[t]{3}{*}{ 13.Co-planarity check } & 1.Transfer the vacuum tray fill with unit from VMI & $0.083 \mathrm{X}_{28}$ \\
\hline & 2.Take out the unit part one by one and put on co-planarity fixture & $0.067 \mathrm{X}_{29}$ \\
\hline & 3.Continue to inductance test with same machine & $0.33 \mathrm{X}_{30}$ \\
\hline \multirow[t]{2}{*}{ 14.Inductance test } & 1.Insert the unit from co-planarity fixture to test cavity. (at the same machine) & $0.12 \mathrm{X}_{31}$ \\
\hline & 2.Transfer the unit into PVC tube after testing process & $0.25 \mathrm{X}_{32}$ \\
\hline \multirow[t]{5}{*}{ 15.Tape \& reel } & $\begin{array}{l}\text { 1.Transfer the PVC tube fill with unit part from co-planarity check and } \\
\text { inductance test workstation to tape and reel process }\end{array}$ & $5.5 X_{33}$ \\
\hline & 2.Take out the unit part from PVC tube and put on magnetic fixture & $1.8 \mathrm{X}_{34}$ \\
\hline & 3.Put the unit part on the slot on the machine one by one to tape and reel & $2.3 \mathrm{X}_{35}$ \\
\hline & 4.Install the carrier tape and run the machine & $1.5 \mathrm{X}_{36}$ \\
\hline & 5.Transfer the carrier tape for packaging & $2.5 \mathrm{X}_{37}$ \\
\hline \multirow[t]{3}{*}{ 16.Packaging } & 1.Transfer the reel that has been seal to the packaging area & $2.5 \mathrm{X}_{38}$ \\
\hline & 2.Take the reel into pizza box, seal and label & $10.5 \mathrm{X}_{39}$ \\
\hline & 3.Transfer the pizza box to the carton box & $2.83 \mathrm{X}_{40}$ \\
\hline
\end{tabular}


There are 41 variables for time equations. For instance, at workstations 1 and 2 , the variable $\mathrm{X}_{2}$ shares between subactivity 3 of workstation 1 and sub-activity 1 of workstation 2 . It shows that both workstations sharing the similar subactivities. Table 4 shows the capacity utilization of inductor component. The analysis shows that the total sub-activities are 49 for all workstations.

Table 4. Capacity utilization of inductor component production processes.

\begin{tabular}{|c|c|c|c|c|c|c|}
\hline No & Sub-Activities & $\begin{array}{c}\text { Practical } \\
\text { Capacity } \\
\text { (min/month) } \\
\end{array}$ & $\begin{array}{l}\text { Used time } \\
\quad(\min )\end{array}$ & $\begin{array}{l}\text { Un-used } \\
\text { capacity } \\
(\min )\end{array}$ & $\begin{array}{l}\text { Capacity Cost rate } \\
\text { (MYR/min) }\end{array}$ & $\begin{array}{l}\text { Un-used cost } \\
\text { (MYR) }\end{array}$ \\
\hline 1 & $\begin{array}{l}\text { Install the core into the chuck of the } \\
\text { winding machine }\end{array}$ & 211,977 & $56,947.32$ & $155,029.68$ & 0.05 & $7,751.48$ \\
\hline 2 & $\begin{array}{l}\text { Move the finish unit and hang to curing } \\
\text { fixture. }\end{array}$ & 211,977 & 37 & 211,940 & 27.53 & $5,834,708.2$ \\
\hline \multirow[t]{2}{*}{3} & $\begin{array}{l}\text { Transfer the curing fixture into the curing } \\
\text { oven }\end{array}$ & 211,977 & 48.1 & $211,928.9$ & 0.05 & $10,596.45$ \\
\hline & Total & 635,931 & $57,032.42$ & $\mathbf{5 7 8 , 8 9 8 . 5 8}$ & 27.63 & $5,853,056.13$ \\
\hline 4 & $\begin{array}{l}\text { Transfer the curing fixture fill of units and } \\
\text { put it into curing oven }\end{array}$ & $52,994.25$ & 48.1 & $52,946.15$ & 0.05 & $2,647.3$ \\
\hline 5 & Curing the epoxy & $52,994.25$ & 105 & $52,889.25$ & 0.05 & $2,644.46$ \\
\hline 6 & Dry the unit below the cool fan & $52,994.25$ & 60 & $52,934.25$ & 0.05 & $2,646.71$ \\
\hline \multirow[t]{2}{*}{7} & Transfer the unit into the tray & $52,994.25$ & 566.64 & $52,427.61$ & 0.05 & $2,621.38$ \\
\hline & Total & 211,977 & 779.74 & 211,197.26 & 0.2 & $\mathbf{1 0 , 5 5 9 . 8 5}$ \\
\hline 8 & Cool down the units after curing process & 282,636 & 60 & 282,576 & 0.04 & $11,303.04$ \\
\hline 9 & $\begin{array}{l}\text { Transfer the units into the tray for lead } \\
\text { cutting process }\end{array}$ & 282,636 & 566.64 & $282,069.36$ & 0.08 & $22,565.55$ \\
\hline \multirow[t]{2}{*}{10} & $\begin{array}{l}\text { Put the part in the vacuum tray after cut } \\
\text { and adjust process }\end{array}$ & 282,636 & 566.64 & $282,069.36$ & 0.078 & $22,001.41$ \\
\hline & Total & 847,908 & $1,193.28$ & $846,714.72$ & 0.198 & $\mathbf{5 5 , 8 7 0}$ \\
\hline 11 & Transfer the drum core into the tray 1 & 211,977 & 944.4 & $211,032.6$ & 0.05 & 10.551 .63 \\
\hline \multirow[t]{2}{*}{12} & Transfer the travel bar into $\mathrm{x}-\mathrm{y}$ table & 211,977 & 112.5 & $211,864.5$ & 0.29 & $61,440.71$ \\
\hline & Total & 423,954 & $1,056.9$ & $422,897.1$ & 0.34 & $71,992.34$ \\
\hline 13 & $\begin{array}{l}\text { Clean the end of EFD needle using soft } \\
\text { material cloth }\end{array}$ & $108,988.5$ & 23.01 & $108,965.49$ & 0.08 & $8,717.24$ \\
\hline \multirow[t]{2}{*}{14} & Remove the travel tray from the machine & $108,988.5$ & 67.5 & 108,921 & 0.05 & $5,446.05$ \\
\hline & Total & 217,977 & 90.51 & $217,886.49$ & $\mathbf{0 . 1 3}$ & $14,163.29$ \\
\hline 15 & $\begin{array}{l}\text { Transfer the travel tray from } x-y \text { table } \\
\text { under CCTV for inspect }\end{array}$ & 141,318 & 67.5 & $141,250.5$ & 0.04 & $5,650.02$ \\
\hline 16 & $\begin{array}{l}\text { Change the cotton bud for cleaning tool if } \\
\text { in bad condition }\end{array}$ & 141,318 & 679.857 & $-538,539$ & 0.089 & $-47,929.97$ \\
\hline \multirow[t]{2}{*}{17} & $\begin{array}{l}\text { Transfer the travel tray to the curing oven } \\
\text { for epoxy curing process }\end{array}$ & 141,318 & 90 & 141,228 & 0.04 & $5,649.12$ \\
\hline & Total & 423,954 & 837.357 & $-256,060.5$ & 0.169 & $-36,630.83$ \\
\hline 18 & $\begin{array}{l}\text { Transfer the travel tray fill of units and } \\
\text { put it into curing oven }\end{array}$ & 70,659 & 90 & 70,569 & 0.05 & $3,528.45$ \\
\hline 19 & Curing the epoxy & 70,659 & 105 & 70,554 & 0.05 & $3,527.7$ \\
\hline \multirow[t]{2}{*}{20} & Dry the unit under the cool fan & 70,659 & 60 & 70,599 & 0.05 & $3,527.95$ \\
\hline & Total & 211,977 & 255 & 211,722 & $\mathbf{0 . 1 5}$ & $10,584.1$ \\
\hline 21 & $\begin{array}{l}\text { Transfer the cool unit with travel tray into } \\
\text { laser machine }\end{array}$ & $105,988.5$ & 202.5 & 105,786 & 0.05 & $5,289.3$ \\
\hline \multirow[t]{2}{*}{22} & $\begin{array}{l}\text { Transfer the units into tray for next } \\
\text { process }\end{array}$ & $105,988.5$ & 944.4 & $105,044.1$ & 0.05 & $5,252.2$ \\
\hline & Total & 211,977 & $1,146.9$ & $210,830.1$ & 0.1 & $10,541.5$ \\
\hline 23 & $\begin{array}{l}\text { Transfer the units from the travel bar onto } \\
\text { vacuum tray }\end{array}$ & 211,977 & 22.5 & $211,954.5$ & 0.05 & $10,597.73$ \\
\hline \multirow[t]{2}{*}{24} & $\begin{array}{l}\text { Transfer the units by using vacuum tray to } \\
\text { avoid fall }\end{array}$ & 211,977 & 944.4 & $211,032.6$ & 0.05 & $10,551.63$ \\
\hline & Total & 423,954 & 966.9 & 422,987.1 & 0.1 & $21,149.36$ \\
\hline 25 & $\begin{array}{l}\text { Transfer the vacuum tray with units from } \\
\text { cut and trim workstation to soldering } \\
\text { process }\end{array}$ & 70,659 & 4,722 & 65,937 & 0.05 & $3,296.85$ \\
\hline 26 & $\begin{array}{l}\text { Transfer the unit from vacuum tray to the } \\
\text { solder fixture }\end{array}$ & 70,659 & 539.8 & $70,119.2$ & 0.28 & $19,633.38$ \\
\hline \multirow[t]{2}{*}{27} & Transfer the unit for cleaning process & 70,659 & 783 & 69,876 & 0.05 & $3,493.8$ \\
\hline & Total & 211,977 & $6,044.8$ & $205,932.2$ & $\mathbf{0 . 3 8}$ & $26,424.03$ \\
\hline 28 & $\begin{array}{l}\text { Transfer the unit from soldering } \\
\text { workstation for cleaning process using } \\
\text { ultrasonic machine }\end{array}$ & $42,395.4$ & 783 & $41,612.4$ & 0.05 & $2,080.62$ \\
\hline 29 & Transfer the unit into the glass beaker fill & $42,395.4$ & 35.7 & $42,359.7$ & 0.089 & $3,770.01$ \\
\hline
\end{tabular}




\begin{tabular}{|c|c|c|c|c|c|c|}
\hline No & Sub-Activities & $\begin{array}{c}\text { Practical } \\
\text { Capacity } \\
\text { (min/month) }\end{array}$ & $\begin{array}{l}\text { Used time } \\
\quad(\min )\end{array}$ & $\begin{array}{l}\text { Un-used } \\
\text { capacity } \\
(\min )\end{array}$ & $\begin{array}{l}\text { Capacity Cost rate } \\
\text { (MYR/min) }\end{array}$ & $\begin{array}{l}\text { Un-used cost } \\
\text { (MYR) }\end{array}$ \\
\hline 30 & $\begin{array}{l}\text { Transfer the glass beaker into the } \\
\text { ultrasonic machine }\end{array}$ & $42,395.4$ & 10.5 & $42,384.9$ & 0.05 & $2,119.25$ \\
\hline 31 & $\begin{array}{l}\text { Transfer out the unit using filter to } \\
\text { remove the isopropyl alcohol and put on } \\
\text { the tray }\end{array}$ & $42,395.4$ & 35.7 & $42,359.7$ & 0.05 & $2,117.99$ \\
\hline \multirow[t]{2}{*}{32} & Dry up the unit under the cooling fan & $42,395.4$ & 60 & $42,335.4$ & 0.05 & $2,116.77$ \\
\hline & Total & 211,977 & 924.9 & $211,052.1$ & 0.289 & $12,204.64$ \\
\hline 33 & $\begin{array}{l}\text { Transfer the unit after cooling process into } \\
\text { VMI process by using magnet strip }\end{array}$ & 353,295 & 112.5 & $353,182.5$ & 0.08 & $28,254.6$ \\
\hline 34 & $\begin{array}{l}\text { Transfer the unit part onto vacuum tray } \\
\text { after inspect }\end{array}$ & 353,295 & 6.3 & $353,288.7$ & 0.04 & $14,131.55$ \\
\hline \multirow[t]{2}{*}{35} & $\begin{array}{l}\text { Transfer the unit part into co-planarity } \\
\text { check }\end{array}$ & 353,295 & 140.7 & $353,154.3$ & 0.04 & $14,126.17$ \\
\hline & Total & $\mathbf{1 , 0 5 9 , 8 8 5}$ & 259.5 & $\mathbf{1 , 0 5 9 , 6 2 5 . 5}$ & 0.16 & $56,512.32$ \\
\hline 36 & $\begin{array}{l}\text { Transfer the vacuum tray fill with unit } \\
\text { from VMI }\end{array}$ & 141,318 & 17.43 & $141,300.57$ & 0.04 & $5,652.023$ \\
\hline 37 & $\begin{array}{l}\text { Take out unit part one by one and put on } \\
\text { co-planarity fixture }\end{array}$ & 141,318 & $1,265.496$ & $140,052.504$ & 0.08 & $11,204.2$ \\
\hline \multirow[t]{2}{*}{38} & $\begin{array}{l}\text { Continue to inductance test with same } \\
\text { machine }\end{array}$ & 141,318 & 0.33 & $141,317.67$ & 0.04 & $5,652.7$ \\
\hline & Total & 423,954 & $1,283.256$ & $422,670.74$ & 0.16 & $22,508.92$ \\
\hline 39 & $\begin{array}{l}\text { Insert the unit from co-planarity fixture to } \\
\text { test cavity. (at the same machine) }\end{array}$ & $105,988.5$ & 0.12 & $105,988.38$ & 0.05 & $5,299.42$ \\
\hline \multirow[t]{2}{*}{40} & $\begin{array}{l}\text { Transfer the unit into PVC tube after } \\
\text { testing process }\end{array}$ & $105,988.5$ & 189 & $105,799.5$ & 0.05 & $5,289.98$ \\
\hline & Total & 211,977 & 189.12 & $211,787.88$ & 0.1 & $10,589.4$ \\
\hline 41 & $\begin{array}{l}\text { Transfer the PVC tube fill with unit part } \\
\text { from co-planarity check and inductance } \\
\text { test workstation to tape and reel process }\end{array}$ & $42,395.4$ & 103,884 & $-61,488.6$ & 0.38 & $-23,365.67$ \\
\hline 42 & $\begin{array}{l}\text { Take out the unit part from PVC tube and } \\
\text { put on magnetic fixture }\end{array}$ & $42,395.4$ & $33,998.4$ & 8,397 & 0.05 & 419.85 \\
\hline 43 & $\begin{array}{l}\text { Put the unit part on the slot on the } \\
\text { machine one by one to tape and reel }\end{array}$ & $42,395.4$ & $43,442.4$ & $-1,047$ & 0.05 & -52.35 \\
\hline 44 & $\begin{array}{l}\text { Install the carrier tape and run the } \\
\text { machine }\end{array}$ & $42,395.4$ & 12 & 42,383 & 1.21 & $51,283.43$ \\
\hline \multirow[t]{2}{*}{45} & Transfer the carrier tape for packaging & $42,395.4$ & 20 & $42,375.4$ & 0.08 & $3,390.03$ \\
\hline & Total & 211,977 & $181,356.8$ & $30,619.8$ & 1.77 & $31,675.29$ \\
\hline 46 & $\begin{array}{l}\text { Transfer the sealed reel into packaging } \\
\text { area }\end{array}$ & $52,994.25$ & 2,000 & $50,994.25$ & 0.66 & $33,656.21$ \\
\hline 47 & $\begin{array}{l}\text { Take the reel into pizza box, seal and } \\
\text { label }\end{array}$ & $52,994.25$ & 84 & $52,910.25$ & 0.06 & $3,174.62$ \\
\hline 48 & Transfer the pizza box into the carton box & $52,994.25$ & 22.64 & $52,971.61$ & 0.06 & $3,178.3$ \\
\hline \multirow[t]{3}{*}{49} & $\begin{array}{l}\text { Transfer the carton box to the warehouse } \\
\text { area. }\end{array}$ & $52,994.25$ & 1,600 & $51,394.25$ & 0.07 & $3,597.6$ \\
\hline & Total & 211,977 & $3,706.64$ & $208,270.36$ & 0.85 & $43,606.73$ \\
\hline & Grand Total & $6,153,333$ & 257,124.02 & $5,217,031.43$ & 32.726 & $6,214,807.07$ \\
\hline
\end{tabular}

Based on the validation analysis in Table 4, the results show that un-used capacity (minute) and un-used cost (MYR) have two signs either positive or negative value. A total positive value of MYR5,834,708.20 at the sub-activity 2 shows that this activity incurs a lot of waste. It is inspected that more capacities are spent for material cost at this sub-activity. The same positive values could be observed at the sub-activities 3 and 1 with the values of MYR10,596.45 and MYR7,751.48, respectively. These positive values show that this workstation 1 contributes toward the waste and has excessive budget allocation. In addition, as observed that the un-used capacity of 211,940 minutes for the sub-activity 2 , it is advised that the production management could revise the cycle time of this sub-activity and hire additional operator at this workstation. The same trend could be monitored for the sub-activities 3 and 1 . Nevertheless, it is observed that, negative values of un-used cost and un-used capacity of -MYR47,929.97 and -538,539 minutes occur at sub-activity 16 . It is suggested, that production management team could plan the optimal budget properly in order to avoid the profit loss. In addition, the operators need to be supervised frequently for the purpose of better target achievement.

Figure 2 illustrates the used and un-used time capacities (minute). the brown colored indicates the used time (minute) and purple colored graph indicates the un-used time (minute) of inductor component. At the drum core winding with auto epoxy (W1), the analysis shows the used capacity of 57,032.42 minutes and un-used capacity of 578,898.58 minutes. The positive value of un-used capacity indicates that the workstation has extra operation time. Therefore, the time accuracy in production line could be achieved if the production or supervisor team can monitor the performance of each operator at the workstation. On the other hand, epoxy inspection at W6 shows the used capacity of 837.357 minutes and un-used capacity of $-256,060.50$ minutes. The negative value of un-used capacity indicates that the time is underutilized in each sub-activity. 


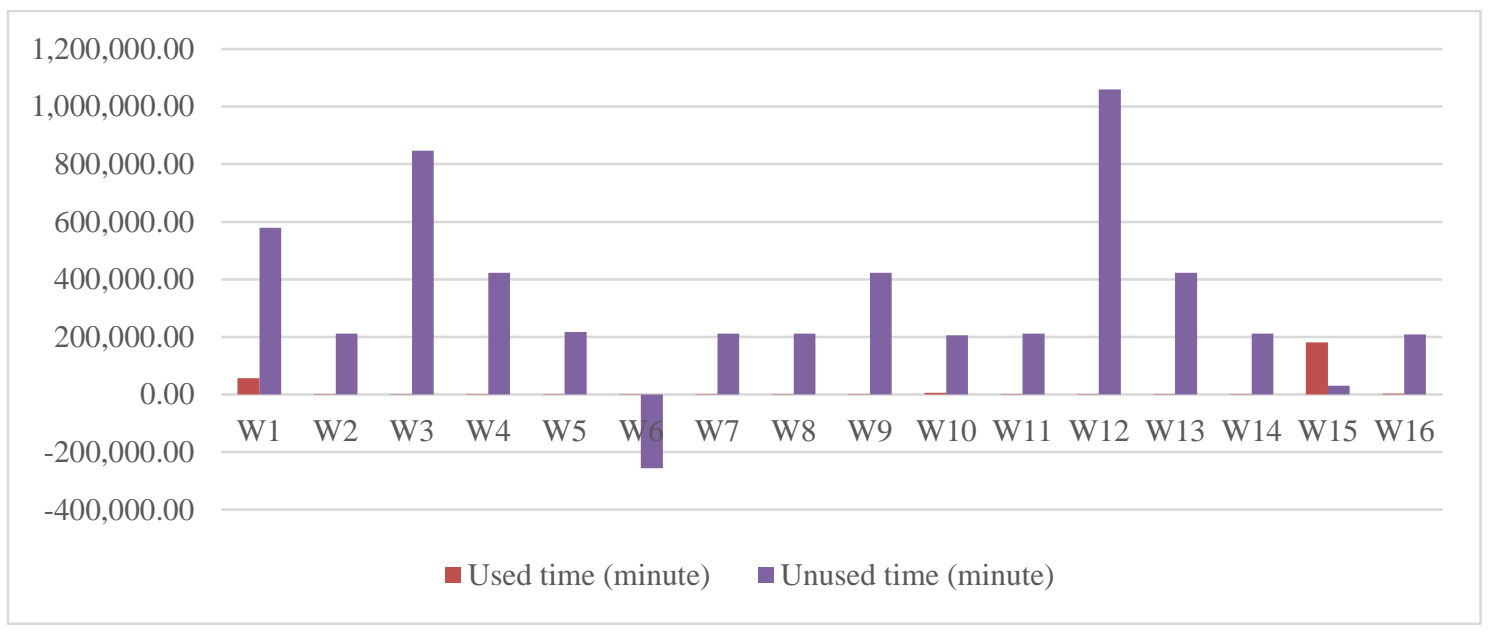

Figure 2. Total used and un-used time capacities (minute) of inductor component production.

Figure 3 illustrates the used and un-used costs (MYR) for the inductor component production. The blue graph indicates the used cost (MYR) and green graph indicates the un-used cost (MYR) of inductor component.

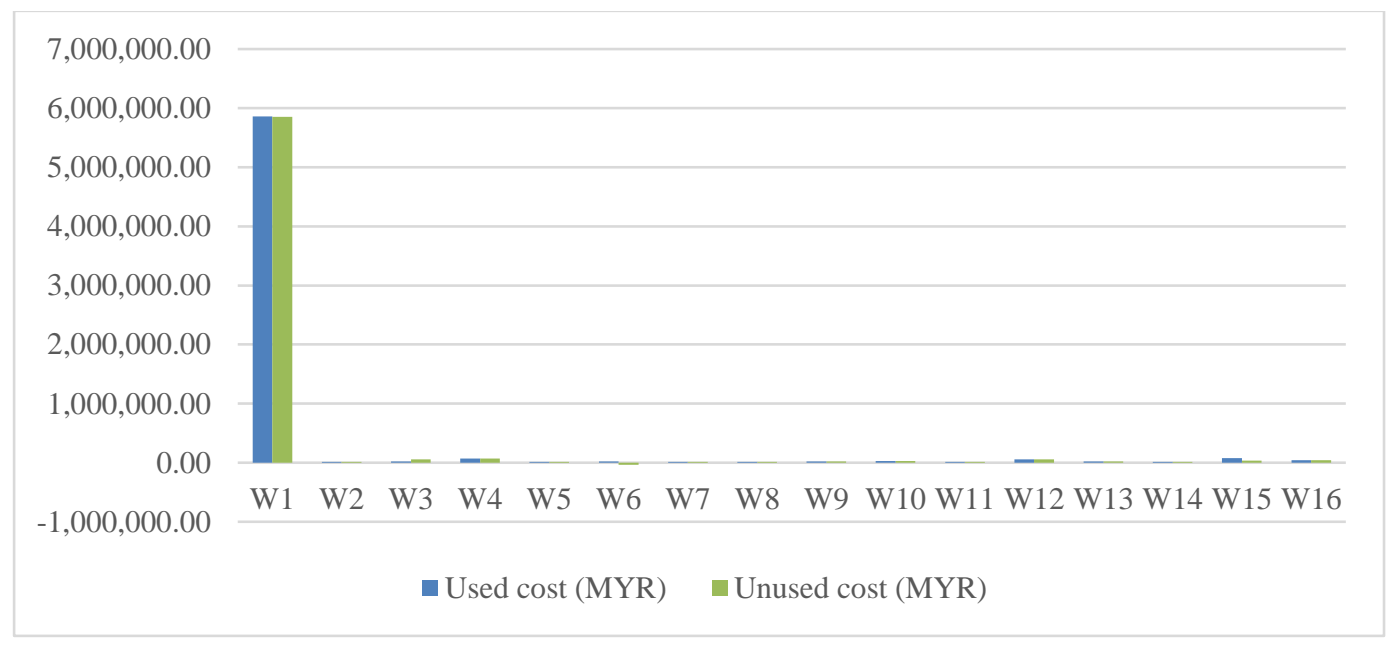

Figure 3. Total used and un-used costs (MYR) of inductor component production.

Based on the analysis, the total used cost of MYR23,749.40 and the total un-used cost of MYR55,870 could be observed at the lead cutting \& lead adjustment (W3). It shows that there is excessive cost at this workstation. It is suggested that, the company should reduce the budget or hire extra workers to achieve the target at this workstation. Further, at the epoxy inspection workstation (W6), the total used cost of MYR23,581.40 and the total of un-used cost of -MYR36,630.83 are recorded from Figure 3. It shows that an extra cost has been used at this workstation. Thus, it is suggested that, the company should allocate properly the resources costs in term of labor, material, maintenance, and consumable costs at each workstation.

\section{CONCLUSION}

This work has successfully applied the method of MTS and TDABC in different workstations on inductor component production.

The implementation of MTS method produces the analysis of normal and abnormal raw data which is sampled based on the random day in each month within a year. The results summarize the threshold of normal and abnormal MD values of each sample. The positive and negative gain values are presented for each month within a year. There are 3 influenced parameters that are consistently affecting the production processes for 10 months in a year which are condition of core, condition of lead part and condition of soldering. On the other hand, there are 2 parameters which are not consistently affecting the production processes namely condition of epoxy and marking condition.

The implementation of TDABC also measures the un-used capacity by constructing the time equation and capacity cost rate. The supplied resources, calculation of the capacity cost rate, determination of estimated time and capacity utilization are important to produce accurate product cost. The capacity utilization shows the grand total of used and unused capacities of time and cost. The grand total of used and un-used capacities of time are 257124.02 minutes and 
5217031.43 minutes, respectively. Grand total of used and un-used costs are MYR6,296,493.10 and MYR6214807.07, respectively.

Eventually, this work concludes that both methods are a great tool and feasible to be implemented in the electronic industry.

\section{ACKNOWLEDGEMENT}

For the financial support given under Collaborative Research Grant Project No. RDU192312, the authors wish to thank Universiti Malaysia Pahang and Universiti Teknologi Malaysia for their support.

\section{REFERENCES}

Abu, M.Y. \& Jamaludin, K.R. (2014). Application of Mahalanobis-Taguchi system on crankshaft as remanufacturing automotive part: a case study. 1st International Materials, Industrial and Manufacturing Conference, 845,883888.

Abu, M.Y., Jamaluddin, K.R. \& Zakaria, M.A. (2017). Classification of crankshaft remanufacturing using MahalanobisTaguchi System. International Journal of Automotive and Mechanical Engineering, 13(2),3413-3422.

Abu, M.Y., Jamaludin, K.R. \& Ramlie, F. (2014). Pattern recognition using Mahalanobis-Taguchi system on connecting rod through remanufacturing process: a case study. 1st International Materials, Industrial and Manufacturing Conference, 845,584-589.

Abu, M.Y., Jamaludin, K.R. \& Zakaria, M.A. (2017). Characterisation of activity based costing on remanufacturing crankshaft. International Journal of Automotive and Mechanical Engineering, 14(2),4211-4224.

Abu, M.Y., Mohd Nor, E.E. \& Abd Rahman, M.S. (2018). Costing improvement of remanufacturing crankshaft by integrating Mahalanobis-Taguchi system and activity based costing. IOP Conference Series: Materials Science and Engineering, 342,1-10.

Abu, M.Y., Norizan, N.S. \& Abd Rahman, M.S. (2018). Integration of Mahalanobis-Taguchi system and traditional cost accounting for remanufacturing crankshaft. IOP Conference Series: Materials Science and Engineering, 342,1-9.

Afonso, P. \& Santana, A. (2016). Application of the TDABC model in the logistics process using different capacity cost rates, 9(5),1003-1019.

Allain, E. \& Laurin, C. (2018). Explaining implementation difficulties associated with activity based costing through system uses. Journal of Applied Accounting Research, 19(1),181-198.

Anzai, Y., Heilbrun, M.E. \& Haas, D. (2017). Dissecting costs of CT study: application of TDABC (time-driven activitybased costing) in a tertiary academic center. Acad Radiol, 24,200-208.

Azmi, I.I., Zaini, S.N.A.M. \& Abu, M.Y. (2019). Application of Mahalanobis-Taguchi system in palm oil plantation. Journal of Modern Manufacturing Systems and Technology, 3,1-8.

Chang, C.T., Chou, Y.Y. \& Zhuang, Z.Y. (2014). Apractical expectedvalue-approach model to assess the relevant procurement costs. Journal of the Operational Research Society.

Cudney, E.A. \& Corns, S.M. (2011). A comparison of finite state classifier and Mahalanobis-Taguchi system for multivariate pattern recognition in skin cancer detection. IEEE Symposium on Computational Intelligence in Bioinformatics and Computational Biology, 1-7.

Cudney, E.A., Paryani, K. \& Ragsdell, K.M. (2006). Applying the Mahalanobis-Taguchi system to vehicle handling. Concurrent Engineering-Research and Applications, 14(4),343-354.

Defourny, N., Perrier, L., Borras, J.M., Coffey, M., Corral, J., Hoozée, S., Loon, J.V., Grau, C. \& Lievens, Y. (2019). National costs and resource requirements of external beam radiotherapy: A time-driven activity-based costing model from the ESTRO-HERO project. Radiotherapy and Oncology, 138,187-194.

Erhun, F., Mistry, B., Platchek, T., Milstein, A., Narayanan, V. G., \& Kaplan, R. S. (2018). Time-driven activity-based costing of multivessel coronary artery bypass grafting across national boundaries to identify improvement opportunities : study protocol, 1-8.

Ghani, N.F.A., Zaini, S.N.A.M. \& Abu, M.Y. (2020). Assessment the unused capacity using time driven activity based costing in automotive manufacturing industry. Journal of Modern Manufacturing Systems and Technology, 4(1),82-94.

Ghasemi, E., Aaghaie, A. \& Cudney E.A. (2015). Mahalanobis Taguchi system: a review. International Journal of Quality \& Reliability Management, 32(3),291-307.

Haas, D.A. \& Kaplan, R.S. (2017). Arthroplasty today variation in the cost of care for primary total knee arthroplasties. Arthroplasty Today, 3(1),33-37.

Hernandez-Matias, J.C. Vizan, A. Hidalgo, A. \& Rios, J. (2006). Evaluation of techniques for manufacturing process analysis. Journal of Intelligent Manufacturing, 17,571-583.

Kaplan, R.S. (2014). Improving value with TDABC. Healthc Financ Manag, 68,76-84.

Kaplan, R.S., Witkowski, M. \& Abbott, M. (2014). Using time-driven activity-based costing to identify value improvement opportunities in healthcare. J Healthc Manag, 59,399-412.

Lea, B.R. \& Fredendall, L.D. (2002). The impact of management accounting, product structure, product mix algorithm, and planning horizon on manufacturing performance. International Journal of Production Economics, 79,279299.

Mohd Safeiee, F.L., Abu, M.Y., Nik Mohd Kamil, N.N. \& Zamrud, N.F. (2020). Diagnosis and costing optimization on 
inductors in electrics and electronics industry. International Manufacturing Engineering Conference \& The Asia Pacific Conference on Manufacturing Systems, 121-127.

Mohd Safeiee, F.L., Abu, M.Y., Nik Mohd Kamil, N.N. \& Zamrud, N.F. (2020). The application of time-driven activity based costing system on inductors in electrics and electronics industry. International Manufacturing Engineering Conference \& The Asia Pacific Conference on Manufacturing Systems,88-95.

Mohd Yazid, A., Khairur Rijal, J., Awaluddin, M.S. \& Emelia Sari. (2015). Pattern recognition on remanufacturing automotive component as support decision making using Mahalanobis-Taguchi system. 12th Global Conference on Sustainable Manufacturing, 26,258-263.

Mohd Zaini, S.N.A. \& Abu, M.Y. (2019). A review on time-driven activity based costing system in various sectors. Journal of Modern Manufacturing Systems and Technology,2,15-22.

Nik Mohd Kamil, N.N. \& Abu, M.Y. (2018). Integration of Mahalanobis-Taguchi system and activity based costing for remanufacturing decision. Journal of Modern Manufacturing Systems and Technology, 1,39-51.

Nik Mohd Kamil, N.N., Abu, M.Y., Zamrud, N.F. \& Mohd Safeiee, F.L. (2020). Proposing of Mahalanobis-Taguchi system and time-driven activity-based costing on magnetic component of electrical \& electronic Industry. International Manufacturing Engineering Conference \& The Asia Pacific Conference on Manufacturing Systems, 108-114.

Nik Mohd Kamil, N.N., Abu, M.Y., Zamrud, N.F., \& Safeiee, F.L.M. (2020). Analysis of magnetic component manufacturing cost through the application of time-driven activity-based costing. International Manufacturing Engineering Conference \& The Asia Pacific Conference on Manufacturing Systems,74-80.

Phan, T.N., Baird, K. \& Su, S. (2018). Environmental activity management: its use and impact on environmental performance. Accounting, Auditing \& Accountability Journal, 31(2),651-673.

Su, C.T. \& Hsiao, Y.H. (2009). Multiclass MTS for simultaneous feature selection and classification. IEEE Transactions on Knowledge and Data Engineering, 21(2),192-205.

Taguchi, G. \& Jugulum, R. (2000). New trends in multivariate diagnosis. Indian Journal of Statistics, 62(2),233-248.

Tsai, W.H. \& Jhong, S.Y. (2019). Production decision model with carbon tax for the knitted footwear industry under activity-based costing. Journal of Cleaner Production, 207,1150-1162.

Wang, Z., Lu, C., Wang, Z., Liu, H. \& Fan, H. (2013). Fault diagnosis and health assessment for bearings using the Mahalanobis-Taguchi System based on EMD-SVD. Transactions of the Institute of Measurement and Control, $1-10$.

Wang, Z., Wang, Z., Tao, L. \& Ma, J. (2012). Fault diagnosis for bearing based on Mahalanobis-Taguchi system. Conference on Prognostics and System Health Management, 1-5.

Woodall, W.H., Koudelik, R., Tsui, K.L., Kim, S.B., Stoumbos, Z.G., Carvounis, C.P., Jugulum, R., Taguchi, G., Taguchi, S., Wilkins, J.O., Abraham, B., Variyath, A.M. \& Hawkins, D.M. (2003). A review and analysis of the Mahalanobis-Taguchi System. Technometrics, 45(1),1-30.

Yu, Y.R., Abbas, P.I., Smith, C.M., Carberry, K.E., Ren, H., Patel, B., Nuchtern, J.G. \& Lopez, M.E. (2016). Time-driven activity-based costing to identify opportunities for cost reduction in pediatric appendectomy. Journal of Pediatric Surgery, 51(12),1962-1966.

Zaini, S.N.A.M., Zheng, C.W. \& Abu, M.Y. (2020). Costing structure improvement using activity based costing in palm oil plantation of Malaysia. Journal of Modern Manufacturing Systems and Technology, 4(1),95-109.

Zamrud, N.F. \& Abu, M.Y. (2020). Comparative study: activity based costing and time driven activity based costing in electronic industry. Journal of Modern Manufacturing Systems and Technology, 4(1),68-81.

Zamrud, N.F., Abu, M.Y., Kamil, N.N.N.M. \& Safeiee, F.L.M. (2020). A comparative study of product costing by using activity-based costing (ABC) and time-driven activity-based costing (TDABC) method. International Manufacturing Engineering Conference \& The Asia Pacific Conference on Manufacturing Systems, 171-178.

Zamrud, N.F., Abu, M.Y., Nik Mohd Kamil, N.N. \& Safeiee, F.L.M. (2020). The impact of capacity cost rate and time equation of time-driven activity-based costing (TDABC) on electric component. International Manufacturing Engineering Conference \& The Asia Pacific Conference on Manufacturing Systems,81-87.

Zheng, C.W. \& Abu, M.Y. (2019). Application of activity based costing for palm oil plantation. Journal of Modern Manufacturing Systems and Technology, 2,1-14.

\section{CONFLICT OF INTEREST}

The author(s), as noted, certify that they have NO affiliations with or involvement in any organization or agency with any financial interest (such as honoraria; educational grants; participation in speakers' bureaus; membership, jobs, consultancies, stock ownership, or other equity interest; and expert testimony or patent-licensing arrangements), or nonfinancial interest (such as personal or professional relationships, affiliations, expertise or beliefs) in the subject matter or materials addressed in this manuscript. 


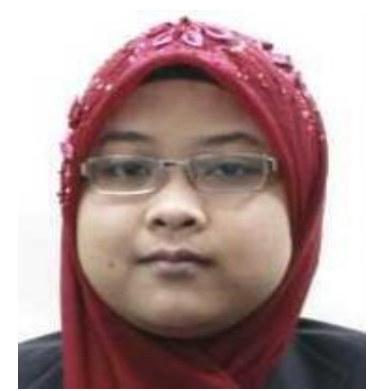

Author's Full Name: Nik Nurharyantie Nik Mohd Kamil

Author's Email: niknurharyantie@gmail.com

Author Professional Bio: Nik Nurharyantie is a research student at Faculty of Manufacturing \& Mechatronic Engineering Technology, Universiti Malaysia Pahang.

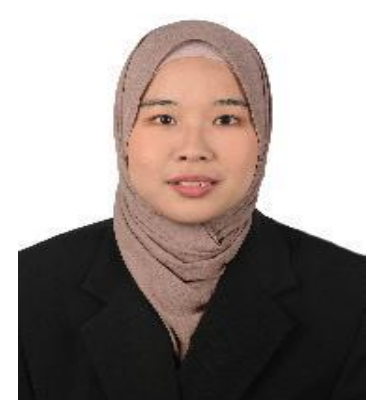

Author's Full Name: Sri Nur Areena Mohd Zaini Author's Email: areena5582@gmail.com

Author Professional Bio: Sri Nur Areena is a research student at Faculty of Manufacturing \& Mechatronic Engineering Technology, Universiti Malaysia Pahang.

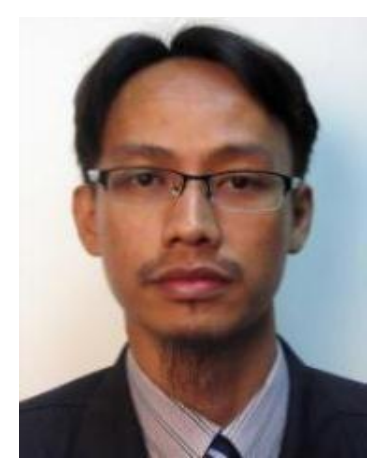

Author's Full Name: Mohd Yazid Abu Author's Email: myazid@ump.edu.my Author Professional Bio: Dr Mohd Yazid Abu is currently serving as a senior lecturer at Faculty of Manufacturing \& Mechatronic Engineering Technology, Universiti Malaysia Pahang. 